resenha

\title{
Niilismo e decadência
}

Samuel Mendonça

Professor da PUC-Campinas

Igor Hideo Kato da Silva

Graduando em Filosofia pela Unicamp

FRANCO, Volpi. O Niilismo. São Paulo: Loyola, 1999.

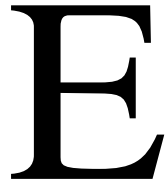

m $O$ Niilismo, Franco Volpi mostra evidências que apontam para as origens do niilismo para, a partir daí, caminhar em sua história e mostrar as diversas formas de como o fenômeno foi tratado e interpretado por diversos intelectuais - dentre artistas, escritores e filósofos -, e como seus modos peculiares de pensar permitiram uma diversidade de perspectivas no desenvolvimento da temática. O primeiro capítulo anuncia o itinerário das páginas que seguem por meio de uma rápida apresentação do niilismo e suas consequências. Expõe, ainda, as concepções de alguns pensadores, dentre os quais, Gottfried Wilhelm Leibniz, Friedrich Wilhelm Nietzsche e Martin Heidegger, que se debruçaram sobre o tema. Assim, dado o mapa da viagem, o autor prossegue com os próximos três capítulos, nos quais procura desvelar as origens do niilismo.

O ponto de partida, no segundo capítulo, é Ivan Turgueniev e seu romance, Pais e filhos, onde é representado o conflito entre a velha e a nova geração, simbolizada pelo niilismo da personagem Bazarov. O que estava em jogo neste romance era justamente o conflito entre as gerações de pais e filhos, isto porque de um lado havia a inspiração humanista e de outro a rebelde e materialista. Franco mostra que, embora Turgueniev tenha definido em seu romance o que é niilismo, não foi o primeiro a fazer, como bem reivindicava, o uso da palavra, e nesse sentido, cita referências mais antigas.

No terceiro capítulo, são apresentadas aparições ainda mais remotas na literatura alemã. Mas, para não se prender à amostra lexical do termo, o autor parte para seu uso exatamente filosófico, cuja base de origem converge, sobretudo, para o estranhamento metafísico do homem, explicado por Blaise Pascal a partir da cosmologia moderna. Ao analisar os debates, do final do século XVIII, que representaram o nascimento do idealismo contra 
resenha

o dogmatismo e o realismo, Franco mostra o modo como o niilismo aliou-se a essa dinâmica, havendo quem lhe atribuísse aspectos negativos, como Friedrich Heinrich Jacobi. O autor ainda aponta outros intelectuais do período romântico que se apropriaram do vocábulo: o pouco conhecido Daniel Jenisch, Friedrich Schlegel - com seus diversos significados para o niilismo e Jean Paul, com sua crítica aos românticos, a quem denominou "niilistas poéticos". Ainda nesse capítulo, lembra Georg Wilhelm Friedrich Hegel e sua importante relação com o niilismo transcendental, ao qual atribuiu caráter obrigatório para conhecer o "nada absoluto", este como "ponto de partida para a atividade filosófica".

O quarto capítulo situa o leitor num momento da história em que o niilismo ultrapassa a fronteira da reflexão estritamente filosófica para ganhar um sentido social. É o que se apresenta na obra do pensador católico Franz von Baader. Ele critica o niilismo - originado, em sua análise, da descontrolada racionalidade científica - por desmanchar verdades sagradas, influenciando a coesão social. Em seguida, aponta-se para a origem do $f e$ nômeno em seu sentido político, na França, em seu período de Revolução.

O niilismo implícito de Max Stirner é o tema do quinto capítulo. Stirner foi um iconoclasta; rejeitou sistemas filosóficos e qualquer coisa que se punha a representar o que não é possível se expressar sobre cada ser, de sua exclusiva unidade. A postura anárquico-libertária que defendia fica clara em seus escritos. Em $O$ único e sua propriedade, por exemplo, ele reivindica a necessidade de afirmação do indivíduo frente aos institutos estabelecidos na sociedade, incluindo o estado e a igreja.

A questão da decadência em Nietzsche é analisada no sétimo capítulo, partindo dos autores que o influenciaram na construção da interpretação pessoal do tema. $\mathrm{O}$ autor atribui essa influência principalmente a Fiódor Dostoiévski, a Turgueniev e a Paul Bourget (para este é dada maior atenção no livro, o qual descreve como ele compreende a decadência, bem como sua análise psicológica a respeito). Fazem-se comparações entre os pensamentos e escritos de Bourget e os do filósofo do eterno retorno para ilustrar a influência que aquele exerceu sobre este. Percebe-se, por exemplo, que ambos 
abordam a decadência partindo de uma perspectiva aristocrática, opondo-se à opinião negativa sobre o fenômeno - visto como "vencido e sem futuro". Franco deixa muito claras as fronteiras dessa influência, quando expõe as reflexões de Nietzsche sobre a transvaloração dos valores, vontade de potência e o eterno retorno. A morte de Deus, por exemplo, anuncia claramente a decadência compreendida como niilismo, no sentido de depreciação dos valores supremos. O autor ainda afirma que é a necessidade de transvaloracão de valores, que nasce da desvalorização dos valores, o sintoma da evolução histórica do pensamento europeu, marca da decadência. A evidente crítica de Nietzsce ao estatuto da verdade é, seguramente, a base do niilismo como decadência, na medida em que esta crítica sinaliza para a vontade de potência que não supõe um mundo verdadeiro ou mesmo que rejeita a possibilidade da "coisa em si".

No capítulo nove, o autor trata de Heinrich Mann e Robert Musil, precoces leitores de Nietzsche, e ainda de Gottfried Broch e de Hermann Benn como escritores cuja intenção era tentar resistir e confrontar o niilismo a fim de superá-lo. Para isso, percebem como eficiente ferramenta a potencialidade estético-literária da forma, aproveitando-se do diagnóstico nietzschiano sobre a decadência e o niilismo. Nesse caminho, Franco descreve as diferentes porém sempre estreitas relações entre cada escritor e os pensamentos nietzschianos.

O décimo capítulo concentra-se no debate filosófico entre Ernst Jünger e Martin Heidegger em torno do niilismo. Tal debate nasce dos diferentes olhares desses pensadores mediante a situação da época, na qual o homem não consegue mais acompanhar a acelerada dinâmica do desenvolvimento tecnológico, e ao perder de vista essa rápida evolução, parece também perder-se. Mesmo levando em conta os pontos de convergência sobre o tema, é o conflito das respectivas reflexões que proporciona "a análise contemporânea mais penetrante do problema", nas palavras do autor, que mostra a riqueza desse embate. Para Heidegger somente um volta ao ser, no dizer e no pensar, promoveria a superação do niilismo, ou seja, o ultrapassamento da "linha", do marco zero no qual o niilismo atinge sua plenitude. 
resenha

Para Jünger, seria necessário primeiro superar a plenitude do niilismo, ultrapassar a linha, para haver uma nova experiência do ser no dizer e no pensar.

No décimo-primeiro capítulo, Franco elucida a relação entre niilismo, gnose e existencialismo ao apontar para importantes intelectuais que, de maneiras diferentes, ocuparam-se profundamente dessa ligação. Jean-Paul Sartre e Albert Camus, por exemplo, são citados por fundirem existencialismo e niilismo a fim de conseguirem esclarecer o absurdo da existência humana. Nesse sentido, suas reflexões são explicadas, inseridas no tema do niilismo gnóstico e estruturadas no gnosticismo. Dessa forma também, são apresentadas as ideias de Émile Cioran, de Émile Bréhier e de Hans Jonas (que foi aluno de Martin Heidegger e de Rudolf Bultman), dentre outros.

No décimo-segundo capítulo, Franco expõe como Carl Schmitt elucida o niilismo moderno e contemporâneo no âmbito da filosofia política. Schmitt divide opiniões com os que têm como uma ameaça para a democracia e para os fundamentos do parlamentarismo, e os que o veem como defensor do Estado forte. De fato, o teórico alemão encara como um problema o declínio da legitimidade do Estado, e aponta para as suas causas, de fundo niilista. Esse capítulo é um resumo panorâmico das ideias desse importante teórico do niilismo.

As abordagens de Alexandre Kojève e Arnold Gehlen sobre o conceito de posthistoire são as selecionadas no capítulo seguinte para se entender melhor as consequências de um olhar de mero observador científico sobre a história. Discute-se a estagnação da sociedade e de sua cultura sem perspectivas de fluxo, de mudança, de continuar caminhando pela história. Por conseguinte, os autores citados promovem a reflexão sobre um "fim da história", a indiferença ao passado que implica em perdas de referências dos valores e assume uma postura niilista que não permite a construção objetiva de um futuro.

O capítulo quatorze focaliza a presença do niilismo na Itália, país cujos pensadores mostraram-se bastante interessados no fenômeno. A existência de várias correntes de pensamento implica uma riqueza de perspectivas e relevantes contribuições na perspectiva teórica. Para ilustrar, citam-se as 
resenha

ideias de Alberto Caracciolo e Luigi Pareyson - cujos focos eram a crítica e o diagnóstico da atualidade a partir do niilismo; Gianni Vattimo - que não culpa o niilismo em si pelo mal estar da sociedade, mas analisa cuidadosamente a própria sociedade, mostrando que não há niilistas para agir, segundo Vattimo, com naturalidade frente ao fenômeno da vida social; e o distinto José Severino, na medida em que suas indagações metafísicas encontram conclusões de caráter niilista bastante originais, o que o destaca dentre outros pensadores.

No último capítulo, Franco pensa a situação contemporânea do relativismo e do ceticismo. Incita-nos a pensar nas causas de um fenômeno que pode ou não ter relação com o estado niilista da sociedade (ou, pelo menos, a vontade de superação deste estado): o fenômeno do apelo ético que se repete regularmente desde o final do século XVI apresentando-se no contexto atual. O autor deixa à mostra a profunda indiferença para com os valores morais e éticos que dá lugar a um novo paradigma coercivo e sufocante - o técno-científico. Elucida-se a situação de crise, mas mostrando-nos um horizonte para a sua superação.

A obra de Volpi apresenta referências precisas e riqueza de conteúdo. $\mathrm{O}$ autor consegue caminhar na direção de seu foco inclusive tratando de temas correlatos ao do niilismo; assim, consegue explicar cuidadosamente cada elemento correlato. Nesse caminho, consegue construir com elegância e rigor a história do niilismo. Sua pesquisa é altamente relevante para estudiosos de filosofia e de áreas que dizem respeito aos fundamentos da existência humana, dado que permite minimamente a compreensão da nossa crise contemporânea. 